\title{
DIGITAL COMMUNICATON AND CONNECTIVITY IN OVERCOMING THE WIDER EFFECT OF THE PANDEMIC CRISIS
}

\author{
Jelena Gajić, \\ Aleksandar Đorđević \\ Singidunum University, \\ Belgrade, Serbia
}

\begin{abstract}
:
Digital collaboration and connectivity are dominant ways of coommunication in the COVID-19 pandemic and postpandemic period in business markets, but they have also proven to be a sucessful tool for sustaining human contact in everyday life as well. It has became apparent that keeping pace with the contemporary digital solutions enables companies to improve and continuously update and optimize their processes and activities in order to meet the needs of different target groups. The aim of this paper is to indicate the importance of digital product management and digital communication possibilities and solutions in business and social environments in order to set a human-centred connectivity. By analyzing the effectiveness of various communication tools for distance collaboration, the researchers came to the conclusion that although the increase in the use of all-things-digital was expected, all of the subsequent, and even some unforeseen effects of the fast transition to digital are reshaping customers' landscape.
\end{abstract}

Keywords:

digital communication, digital connectivity, remote collaboration platforms, pandemic crisis.
Correspondence:

Jelena Gajić

\section{INTRODUCTION}

Before the global pandemic crisis, different studies indicated that digitalization had started being a common issue for all industries and, some which were moving faster than others. Yet, a wider consensus is that most industries were moving not nearly as fast as possible. This new digital reality has indicated who participates in the future connectivity and communication in the business and consumer markets.

Although the focus of the paper was to analyze digital collaboration aspects among selected professional environments, it is expected that the transition to a more digital and more connected workplace will also transfer over to the consumer markets.

Digital globalization enables connections between organizations, nations, industries, companies, and individuals around the world using data, information, knowledge and ideas. Various digital technologies (ICT, the Internet, cloud services, data analytics...), communication tools (Meetings, Webinars...), Time Management and Productivity tools, CRM tools and other digital platforms (e-commerce, online marketplaces, etc.), support these connections in order to make intercompany and intracompany activities faster, more flexible and efficient (Luo, 2021, Cantwell, 2009). 


\section{DIGITAL TRANSFORMATION}

Digitalization is the driving force of globalization in all areas of a business in order to create new operation processes, services, technological devices, communication and collaboration tools and possibilities (Srai, et al. 2019). Improving business processes, producing and delivering competitive customer values in the digital environment require investments in processes, human resources and in technologies.
According to official data, most IT companies (78\%) and energy companies (77\%) are trying to meet the challenges of the COVID-19 pandemic by applying digital transformation faster than other companies (STATISTA, 2021).

Graph 1. COVID-19 pandemic and digital transformation in different companies

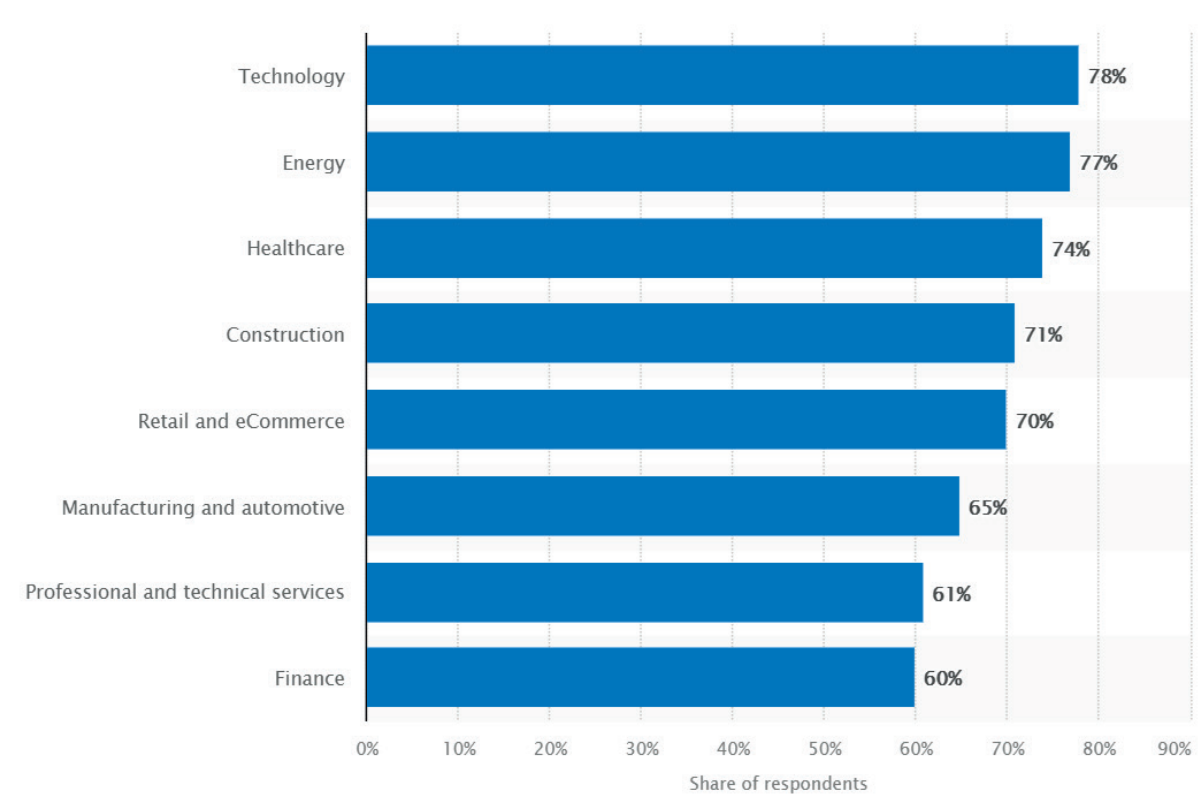

Suorce: (STATISTA, 2021)

Advanced analytics and artificial intelligence enable companies to transform their activities, processes digitally, meet current market trends, and customer needs. Pandemic situation and appropriate measures have challenged economies, social and cultural lives, political situations and education. The whole situation has motivated cooperation between scientists and managers in order to be creative and innovative providing alternative communication tools and collaborative solutions in business activities and in consumer buying processes. At the same time, competitive companies have to build collaborative advantages in the global business eco-system of the digital age (Luo, 2021; Duan,et al. 2019).

The emergence of the corona virus and pandemic have affected all spheres of human life. At the same time, they have also affected the consumer's relationship and behavior within consumer buying processes, access to the purchase process itself and consumer habits when purchasing (Sheth, 2020). According to McKinsey Global Survey, it was found that at least $80 \%$ of their customer connections and interactions are digital in nature (McKinsey Global Survey, 2021).
At the end of 2020, the Ernest \& Young company conducted a survey on global level and in Serbia as well, and the topic was "EU index of changing consumer habits". The research in the Republic of Serbia was conducted on a sample of 1,000 respondents. The subject of the analysis was the impact of COVID-19 on different areas: on the performance of daily activities; consumption; purchase criteria; the way of doing business; the use of banking services; the use of transport and the modes of travelling; on eating outside the home; on food purchase and preparation; on exercise and on the changes in habits and lifestyle (EY, 2021, Sheth, 2020).

Analyzing the impact of the COVID-19 pandemic, the most important data about the way of doing business, the representatives of the auditing and consulting company EY found that $34 \%$ of the respondents believed that they would work from home more often, $26 \%$ that they would have a more flexible job, $24 \%$ that they would use video conferencing more often, $23 \%$ that they would attend online lectures, while $23 \%$ believed they would be less willing to work in a shared space (EY, 2021). 


\section{DIGITAL ADAPTATION}

New digital environment implies different kinds of digital forces that enable digital global collaboration. According to Luo, important digital forces are: intangible flows of knowledge and data, quickened access to and diffusion of knowledge, central role of digital infrastructure, fortified consumer power in shaping global business and a remarkable rise of a large number of small Multinational Enterprises (Luo, 2021; Castagna, et al. 2020).

Internally, contemporary organizations should develop cross-collaboration and try to diffuse knowledge within the organization. Also, digital connectivity and integration demands sharpened organizational abilities, architecture, and structure to perform global resource mobilization (Luo, 2021).

\section{SURVEY METHODOLOGY AND SAMPLE DEFINITION}

The sample included 40 companies in various industries working primarily in Serbia, although most of them had different levels of presence in the Adriatic region. The sampled companies included both companies founded by the state, as well as privately held entities. Due to the constraints by the GDPR and contractual agreements with companies, the particular company names as well as fine, pinpointed statistics were intentionally generalized, in order to protect companies' privacy but at the same time retain the intended research outcomes. Also, all the statistical results of the survey are presented as screenshots from the Power BI analytical tool that gathered and visualized the analyzed data sources.

\section{THE ROADMAP FOR DIGITAL BUSINESS TRANSFORMATION}

In terms of the workforce size, the smallest company employed about 200 employees, whilst the largest system employed over 3,000 employees.

The assessed sample used Microsoft licensed communication tools, namely: MS Teams, MS Meetings, MS Teams Phone System, MIP, MS Exchange, MS Yammer, MS 365 Apps and MS Outlook mobile.

The key parameter for the usage of analytics was the number of active monthly users, as well as the usage of Microsoft cloud services and applications hosted on Microsoft cloud (Microsoft Azure).
Such a broad and fairly undifferentiated sample was justified through the fact that the core of the research focuses on global communication challenges caused by the health crisis, that wouldn't vary much across different industries, companies' sizes, etc.

In order to assess how the COVID crisis had affected the communication within the companies, the starting hypothesis assumed that the companies had engaged more heavily in the use of communication tools that had enhanced their communication capacities. For this purpose, the sample included companies that had an increased usage of the mentioned communication software tools, or had just started using the mentioned tools.

The usage data analyzed the time period from roughly Q2 of the fiscal 2020. until Q3 of the fiscal 2021. Prior periods were not taken into consideration for this particular research due to a narrow research focus and technical sample data constraints. However, the conclusions of this paper can and should be used to trace out future research efforts that would encompass a longer time window.

\section{RESULTS AND DISCUSSION}

The initial hypothesis that established the expectations that the use of communication tools would increase with the new circumstances imposed by the health crisis has been positively confirmed by the sampled companies' usage statistics. 


\section{$<$ Back to report $\mid$ HISTORICAL ACTIVE USERS \& USAGE}

Service Name Exchange Intune Microsoft 365 Apps MIP SharePoint Teams Teams Meetings

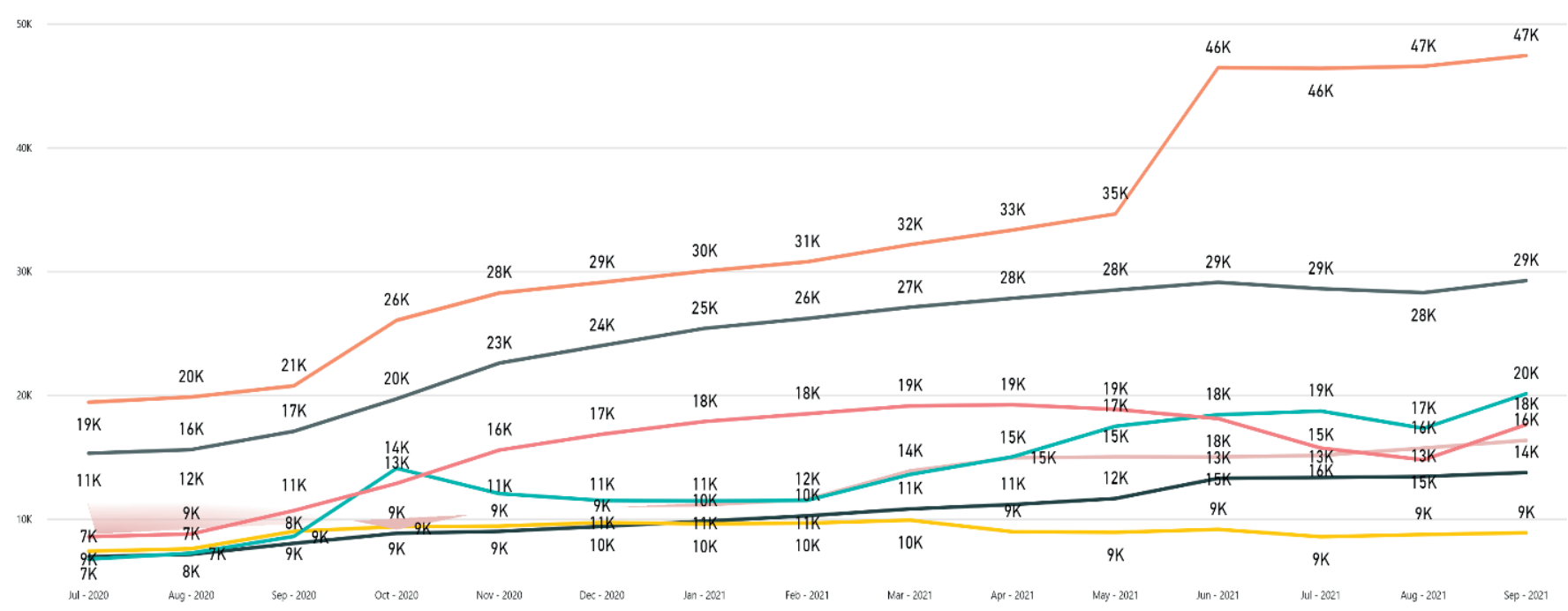

Naturally, the Office 365 usage is leading a steady growth in terms of the total volume of usage, due to its usecase scenarios that overpass collaboration tools only; Office 365 contains productivity tools that are widely used regardless of the work environment. Interestingly though, the use of Teams Meetings has been constantly growing even beyond the ease down of the COVID-related measures that allowed companies to start getting back into the office environment steadily. This particular trend communicates the widely-accepted change in corporate culture and behavior, as communication is now obviously shifting towards more digitally-oriented channels, rather than the traditional ways colleagues use to meet and communicate in person.

Furthermore, by more narrowly analyzing the tools that are aimed at distance collaboration, we can see the obvious positive gap in the usage of Teams Meetings compared to some other tools, in terms of the growing number of active monthly users.

Graph 3. Usage trends by the select collaboration-focused tools and applications for the period June 2020 - September 2021

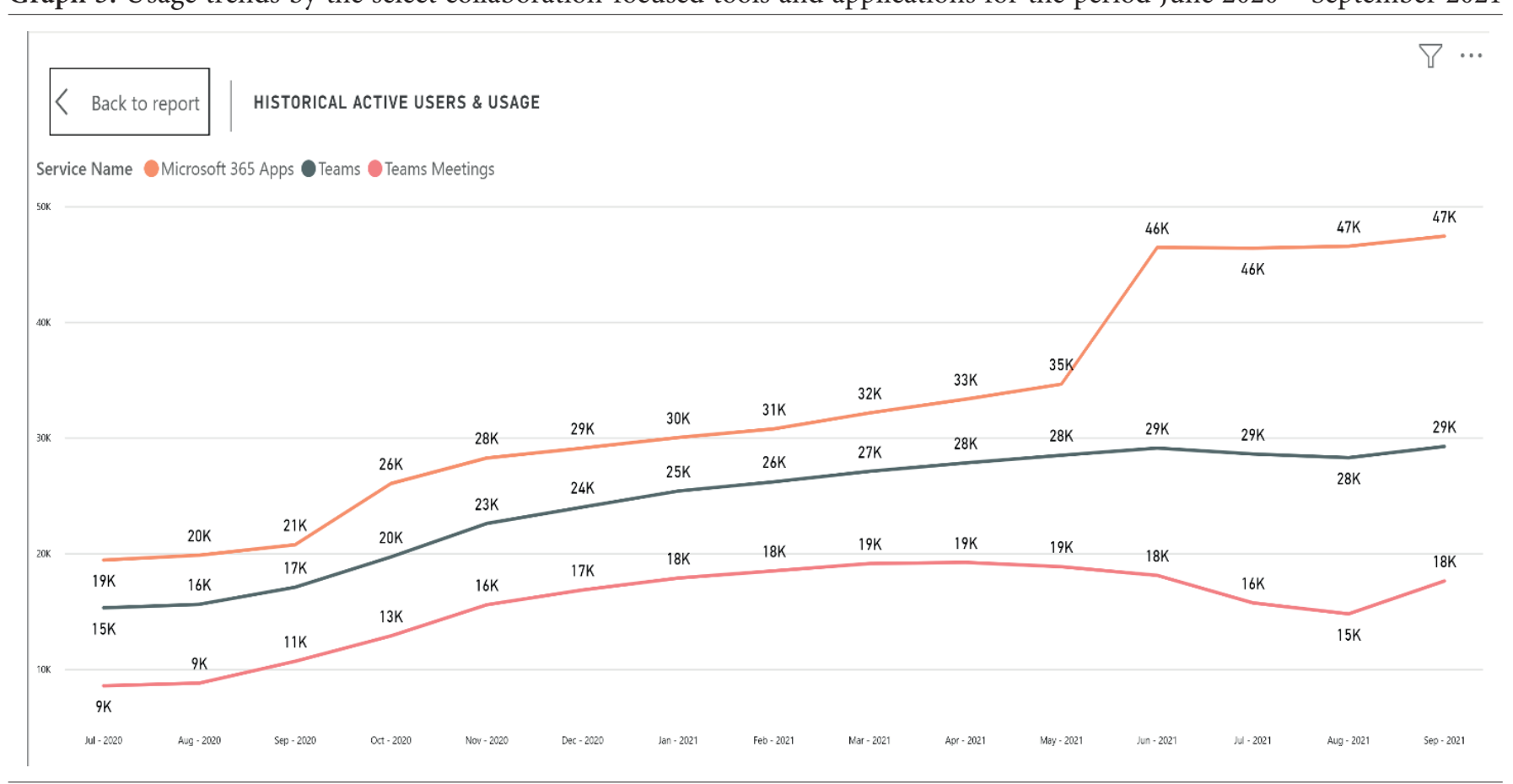


Interestingly, we can see the Teams' slope was heading to a slight decline past May 2021, while the Teams Meeting had a continuous, although not steady, growth throughout the observed period. This insight is of a particular value to marketers, as it reflects a change in the way people in the corporate environment now communicate. This is especially applicable in the way marketers should address and streamline B2B communication via digital channels, as the change in behavior seems to be permanent or long-term, at the very least.
In order to address the assumption that the sample methodology might be biased in a way that privately held companies would be faster to adjust to the technological trend of communicating faster through new, digital collaboration tools, below is the representation of usage statistics for a large enterprise system majorly owned by the State, and employing several thousand employees.

Graph 4. Usage statistic for the last 18 months within a large, primarily state-owned enterprise system

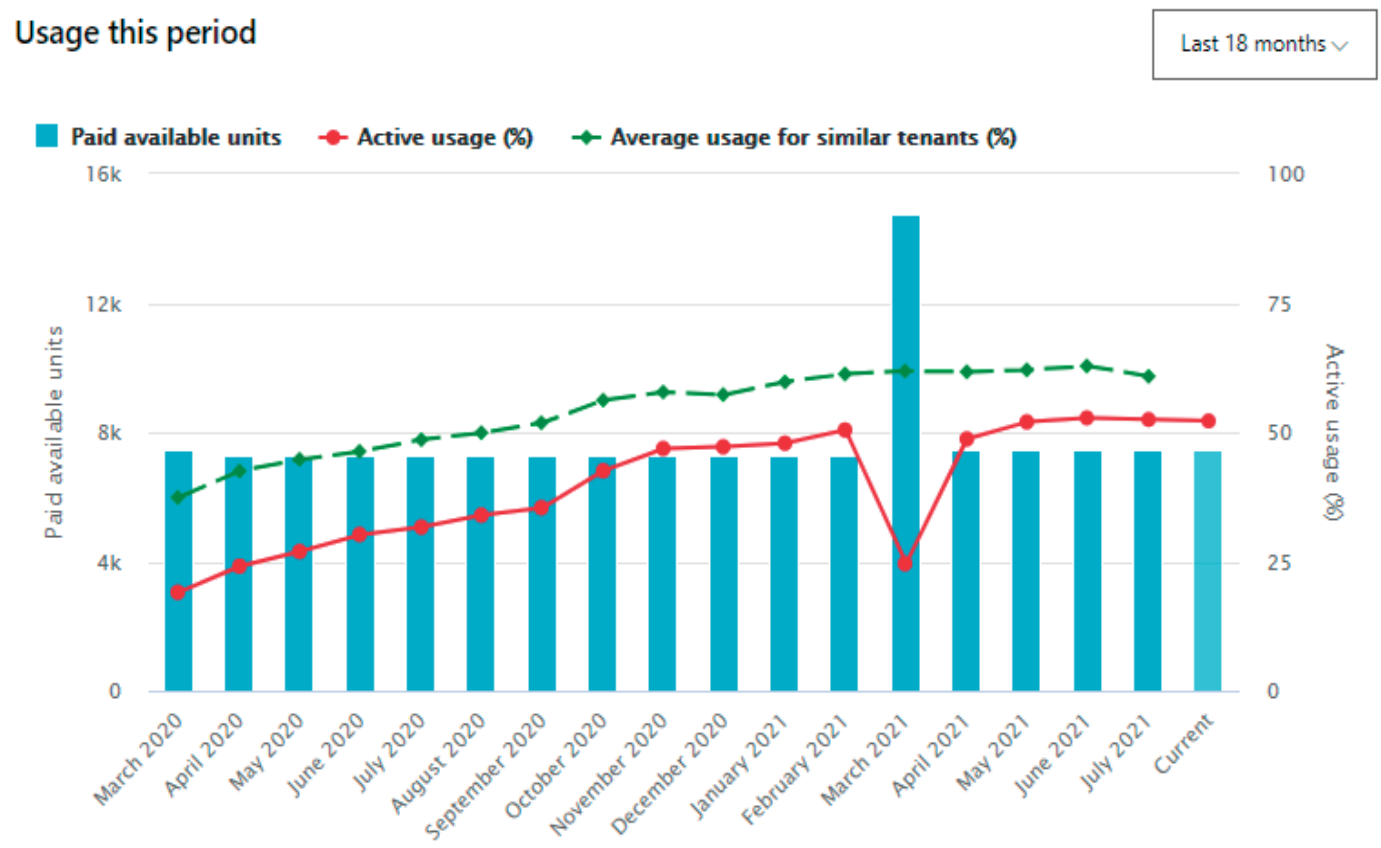

We can see how the number of used software licenses is somewhat lower than the total number of the available licenses. This is a completely common case, and companies - especially large enterprise systems - often need time to utilize all the possibilities of the bundled software their organization is subscribed to. Nonetheless, the increasing number of users is a trend that undoubtedly communicates the shift in the organizational behavior of this system. The big spike in the number of paid units in March 2021 (and a consequential dip in the number of active users), could probably be explained by the license renewal, or migration to another domain, and could very well simply be ignored by marketers as irrelevant.
What is important is that this graph supports the argument that the recent health crisis is driving even the not-so-agile organizations towards an increased organizational effectiveness, as well as a permanent change in the way they communicate.

In parallel, we can see that although the sheer volume of usage is significantly different, at a privately owned enterprise (a fairly large bank in Serbia), the trend of increased number of users had been growing until it stabilized at about $80 \%$ of the usage in the organization. 


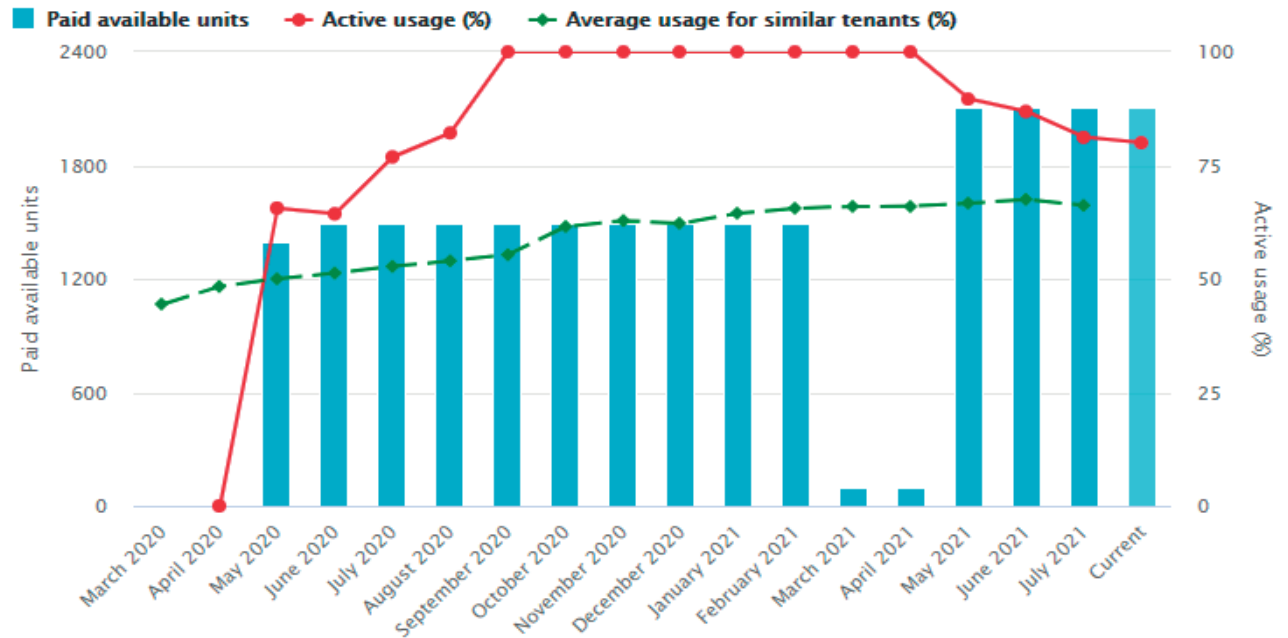

Finally, a cumulative overview of the market for distance collaboration tools growth is confirming the hypothesis that the COVID crisis has pushed organizations to shift their communication focus towards a more digital channel utilization. The overview of the total number of Azure cloud consumers, reflected through generated revenues, is undoubtedly showing the significant growth in one parameter that reflects an increased online communication.

Although this data itself is not by any means sufficient to draw any definite conclusions in analyzing whether there is a meaningful definition in how organizations communicate based on their ownership structure, it certainly establishes a frame of questions to be addressed in the future, a more narrowed down research.

\section{CONCLUSION}

It is safe to conclude that the COVID based crisis has shifted the paradigm to all-things-digital and put it on a fast track. This change is most obviously reflected through the fast pace of technological adoption: this research has confirmed that the utilization of the already purchased software for collaboration was exceptionally fast, regardless of whether we are analyzing the privately held or State-run organizations. This has definitely confirmed that Digital collaboration and connectivity are now definitely dominant ways of coommunication in the (post) COVID-19 pandemic period, especially in the business markets, but in consumers' one as well (Sheth, 2020). Therefore, digitalization was trying to meet different kinds of requirments for companies and customers as well, during the pandemic. According to different kinds of surveys, spending on digital transformation is predicted to be 1.78 trillion dollars (STATISTA, 2021).
According to Luo, digital communication and connectivity enable more opportunities for those companies that are completely prepared digitally and strategically (Luo, 2021).

\section{LITERATURE}

Cantwell, J.A. (2009) Inovation and Information technology in the MNE, The Oxford Handbook of International Business (2 ed.), Oxford University Press, Oxford UK

Castagna. F., Centobelli. P., Cerchione, R., Esposito. E., Oropallo. E., \& Passaro. R. (2020) Customer Knowledge Management in SMEs Facing Digital Transformation. Sustainability, 12(9), 3899.

Duan. Y., Edwards. J.S. and Dwivedi.Y.K., (2019) Artificial intelligence for decision making in the era of Big Dataevolution, challenges and research agenda. International Journal of Information Management, 48, pp.63-71.

Luo. Y. (2021). New OLI advantages in digital globalization, International Business Review

STATISTA (2021) Retrieved from https://www.statista.com/ statistics/1200484/covid-digital-transformation-processindustry/

Sheth J.(2020): Impact of COVID-19 on consumer behavior: Will the old habits return or die? Journal of business research, 117, 280-283.

Srai, J., Lorentz, H. (2019) Developing design principles for the digitalisation of purchasing and supply management. J. Purch. Supply Manag. 25(1), 78-98.

EY(2021): EY indeks promena navika potrošača, https://assets.ey.com/content/dam/ey-sites/ey-com/sr_rs/topics/ consulting/pdf/ey-indeks-promena-navika-potrosasakompresovano.pdf?download, 17.07.2021

McKinsey Global Survey (2020) Retrieved from COVID-19 digital transformation \& technology $\mid$ McKinsey 